\title{
A huge primary pleomorphic liposarcoma of the left atrium
}

\author{
Dariusz Plicner ${ }^{1}$, Jarosław Stoliński ${ }^{1}$, Hubert Hymczak ${ }^{2}$, Bogusław Kapelak ${ }^{1,3}$, Roman Pfitzner ${ }^{1,3}$ \\ ${ }^{1}$ Department of Cardiosurgery, John Paul II Hospital, Krakow, Poland \\ 2Department of Anesthesia, John Paul II Hospital, Krakow, Poland \\ ${ }^{3}$ Institute of Cardiology, Jagiellonian University Medical College, Krakow, Poland
}

Kardiochirurgia i Torakochirurgia 2017; 14 (2): 139-140

Primary cardiac tumors are exceptionally rare. Metastases of the heart occur 20-40 times more frequently than primary neoplasms [1]. Among primary cardiac tumors in adults, approximately $25 \%$ are malignant, and nearly all are sarcomas. Primary cardiac sarcomas are much more commonly reported than primary liposarcomas [2]. Primary liposarcomas of the heart are extremely rare neoplasms found in only about $1 \%$ of all primary malignant cardiac tumors. Only a few cases of primary cardiac liposarcoma have been reported [3-5].

We report a case of resection of left atrial primary liposarcoma.

A 21-year-old woman (gravida 1, para 1, 0 Rh plus) was admitted with a presumptive diagnosis of acute endocarditis and mitral valve vegetations. On admission she presented an 8-week history of progressive dyspnea, malaise, fever, cough and sore throat. During this time she was treated with antibiotics without results. She was free of cardiovascular disease or other symptoms until fever developed. Auscultation revealed tachycardia, continuous murmur (Levine 4/6) over the apex and rales over all pulmonary fields. Electrocardiography showed tachycardia with normal 12-lead ECG. Chest roentgenogram showed a small tent-shaped adhesion over the left diaphragm dome. Other $X$-ray findings were within the normal range. The laboratory examination on admission revealed anemia (with $\mathrm{Hb}$ $9.1 \mathrm{~g} / \mathrm{dl}$ and Hct 29.6\%) and thrombocytopenia (with Plt $\left.57.5 \times 10^{3} / \mu \mathrm{l}\right)$. Transthoracic two-dimensional echocardiography revealed a large mass extending from the left atrium through the mitral valve to the left ventricular outflow tract (Fig. 1).

The patient underwent an emergency operation. Surgery was performed through a median sternotomy with cardiopulmonary bypass and mild hypothermia. The tumor originated from the wall of the left atrium, between the right superior and right inferior pulmonary veins. It extended to the left ventricle outflow tract and almost completely blocked the mitral valve orifice. En bloc resection was performed and the tumor pedicle was shaved from the atrial myocardium. The tumor was a $25 \mathrm{~cm}$ long, cone-shaped structure with a $4 \mathrm{~cm}$ diameter base and $0.5 \mathrm{~cm}$ diameter apex (Fig. 2). Aorta cross clamping time was $45 \mathrm{~min}$ and time of extracorporeal circulation was 70 min.

Pathologic analysis of the resected specimen revealed neoplasma malignum anaplasticum mesenchymale-differentiated pleomorphic liposarcoma (Fig. 3). Bacteriological examinations of the tumor and patient's blood were negative for both aerobic and anaerobic microorganisms.

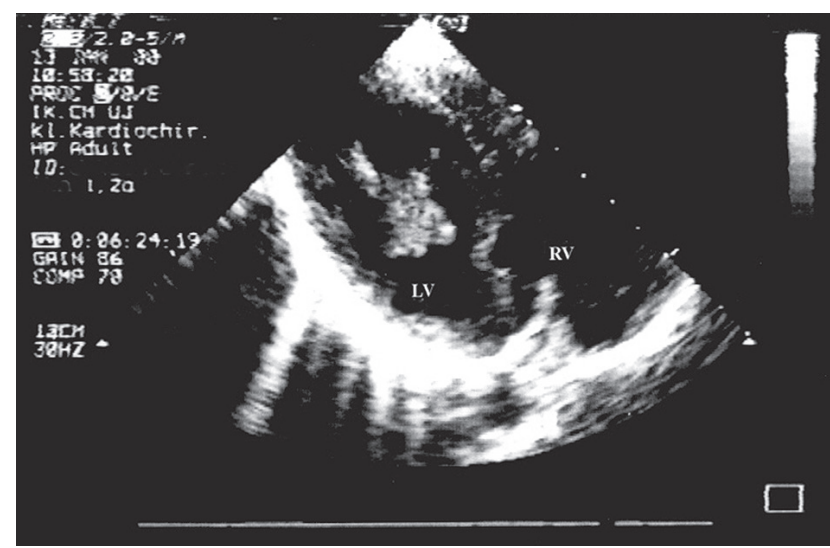

Fig. 1. Echocardiography showing a large tumor filling the left atrium and left ventricle

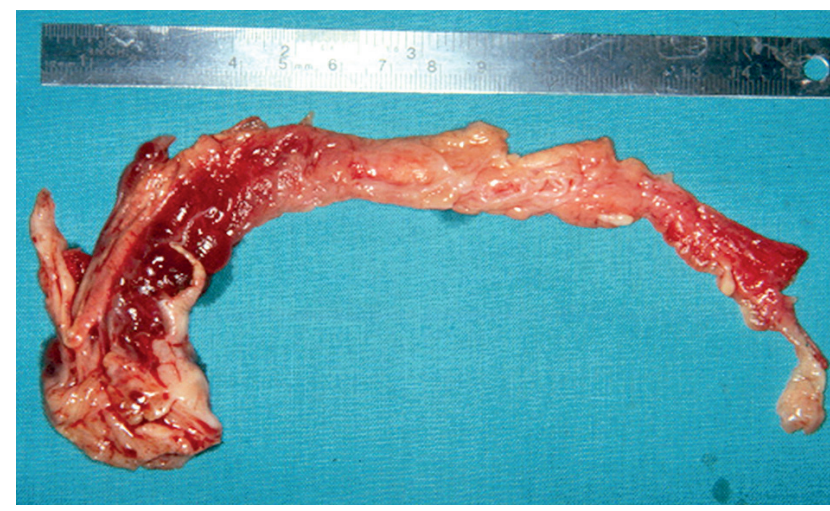

Fig. 2. Macroscopic view of resected tumor

Address for correspondence: Dariusz Plicner MD, PhD, Department of Cardiosurgery, John Paul II Hospital, 80 Prądnicka St, 31-202 Krakow, Poland, phone: +48 1261430 75, e-mail: plicner@outlook.com

Received: 30.10.2016, accepted: 20.01.2017. 


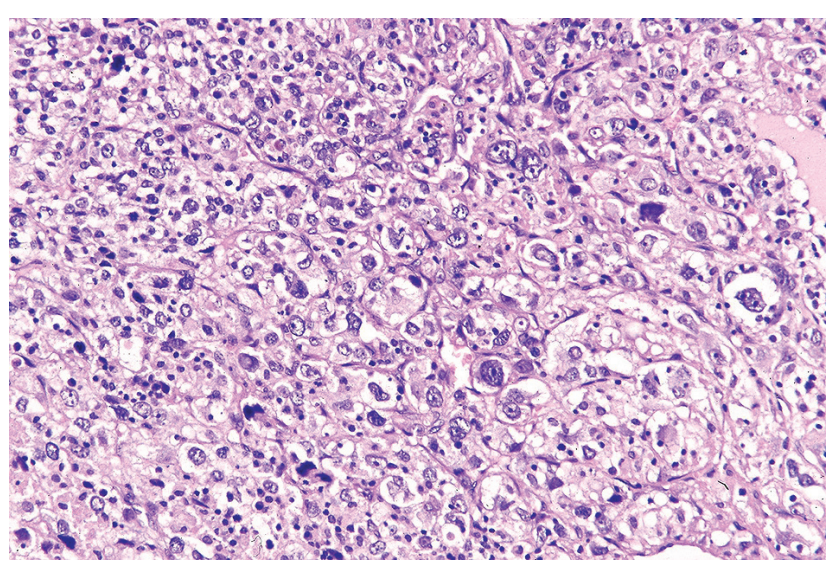

Fig. 3. High-power view showing histologic features of the left atrial pleomorphic liposarcoma

The patient made an eventful post-operative recovery. She was studied extensively to localize peripheral metastases, and postoperative cerebral, thoracic, and abdominal computed tomographic scans showed absence of distant metastases. The patient was discharged 18 days postoperatively, with improvement of her symptoms. She was advised to follow up with chemotherapy. In spite of the recommended adjuvant treatment she did not continue therapy in the oncology department. The patient died 8 months after being discharged. An autopsy was not performed.

In this report, we presented a very rare case of left atrium pleomorphic liposarcoma. Primary malignant cardiac tumors are very rare diseases. Most of these tumors are angiosarcomas, rhabdomyosarcomas, malignant mesotheliomas, and fibrosarcomas. According to a survey conducted by McAllister and Fenoglio, primary liposarcoma of the heart constitutes $0.2 \%$ of all cardiac tumors [1]. The World Health Organization currently recognizes four subtypes of primary liposarcoma: well-differentiated (or atypical lipoma), myxoid, pleomorphic and dedifferentiated [6]. Of those, the pleomorphic form is the rarest type and its malignant potential is very high [7].

In our hospital, 306 patients with a diagnosis of primary cardiac tumor have been operated on since 1979. The case described above was the first case of liposarcoma tumor.

Before common use of echocardiography, computed tomography and magnetic resonance, most primary cardiac tumors were diagnosed during autopsy. Because of its common availability and high sensitivity, two-dimensional echocardiography seems to be a great diagnostic tool in recognizing cardiac tumors. The most common presump- tive diagnosis of cardiac tumor is myxoma. The reason is that myxomas account for $40 \%$ of all primary cardiac tumors and can occur in any chamber of the heart but most often in the left atrium $-70 \%$ of all cases. Because neoplasms are often accompanied by systemic fever, another common diagnosis on admission is active endocarditis with valve vegetations. The final diagnosis is always made by histological examination.

Although surgical intervention is rarely of benefit in malignant cardiac tumor cases, in selected patients, surgical resection of the tumor should be considered, even if metastases exist. This is recommended because death may occur due to obstruction of flow within the heart or embolization. Surgical therapy is often limited to relief of recurrent pericardial effusions or occasionally cardiac tamponade. In non-life-threatening conditions, surgical treatment does not prolong survival. In our case, survival after surgical resection of the tumor without adjuvant radiation or chemotherapy was as poor as in patients with this kind of follow-up therapy [8].

The current study reported a very rare case of a cardiac primary liposarcoma. There is no evidence available to help in the management of such patients. Surgical resection is the primary modality. Cooperation between cardiologists, cardiac surgeons and oncologists may lead to the identification of an optimal treatment.

\section{Disclosure}

The authors report no conflict of interest.

\section{References}

1. McAllister HA, Fenoglio JJ Jr. Tumors of the cardiovascular system. In: Atlas of Tumor Pathology. $2^{\text {nd }}$ series. Armed Forces Institute of Pathology, Washington DC 1978.

2. Banyś A, Wągrowska-Danilewicz M, Kordek R, Kasprzak J, Peruga Z, Jaszewski R. Left atrial and ventricular malignant tumor In a 62-year-old woman: a case report. Kardiochir Torakochir Pol 2010; 7: 443-448.

3. Macedo-Dias JA, Queiryoz Machado F, Vouga L, Goncalves V, Gomes R. Liposarcoma of the heart. A case report. Am J Cardiovasc Pathol 1990; 3: 259-263.

4. Nzayinambaho K, Noe H, Brohet C, Cosyns J, Reding R, Sonnet J, Chalant C. Primary cardiac liposarcoma simulating a left atrial myxoma. J Thorac Cardiovasc Surg 1985; 33: 193-195.

5. Uemura S, Watanabe M, Iwama H, Saito Y. Extensive primary cardiac liposarcoma with multiple functional complications. Heart 2004; 90: e48.

6. Christopher DM, Unni KK, Mertens F. WHO classification of tumors. Pathology and genetic of tumors of soft tissue and bone. IARC Lyon 2002; 35-46.

7. Georghiou GP, Shapira Y, Tobar A, Vidne BA, Sahar G. Primary cardiac pleomorphic sarcoma: an aggressive tumor. Isr Med Assoc J 2005; 7: 470-471.

8. Llombart-Cussac A, Pivot X, Contesso G, Rhor-Alvarado A, Delord JP, Spielmann M, Türsz T, Le Cesne A. Adjuvant chemotherapy for primary cardiac sarcomas: the IGR experience. Br J Cancer 1998; 12: 1624-1628. 